\title{
Pleuroperitoneal Leak in Peritoneal Dialysis: A Series of 10 Cases
}

\author{
Anissa Benjaafar, Manal Chattahi, Kaoutar Sebti, Tarek Bouattar, Naima Ouzeddoun, \\ Rabia Bayahia, Loubna Benamar
}

Nephrology Department, Ibn Sina Hospital Mohammed V University, Rabat, Morocco

Email: anissabenjaafar@gmail.com

How to cite this paper: Benjaafar, A., Chattahi, M., Sebti, K., Bouattar, T., Ouzeddoun, N., Bayahia, R. and Benamar, L. (2021) Pleuroperitoneal Leak in Peritoneal Dialysis: A Series of 10 Cases. Open Journal of Nephrology, 11, 403-411.

https://doi.org/10.4236/ojneph.2021.113033

Received: July 19, 2021

Accepted: September 10, 2021

Published: September 13, 2021

Copyright $\odot 2021$ by author(s) and Scientific Research Publishing Inc. This work is licensed under the Creative Commons Attribution International License (CC BY 4.0).

http://creativecommons.org/licenses/by/4.0/

\begin{abstract}
Pleuroperitoneal Leak (PPL) is a rare, but serious complication of Peritoneal Dialysis (PD). It is the result of congenital or acquired communication between the 2 peritoneal and pleural cavities, and is often linked to high Intra-Abdominal Pressures (IAP). Its diagnosis is clinical, radiological and biological. In this article, we report 10 cases of PPL identified over a period of 13 years (2006-2019), that is to say, a prevalence of 5\%. We suspected the diagnosis of FPP in front of dyspnea alone in 5 cases (50\%), dyspnea associated with cough in 4 cases (40\%). Catheter migration was reported in 5 patients ( $50 \%$ of cases). None of our patients presented with peritonitis before FPP. The pleurisy was right in 7 patients (70\%). The exploratory puncture of the Pleural Fluid (PF) was performed in 3 patients, and which showed results consistent with the PD fluid. The drop in infusion volumes was required in 4 patients (40\%) with an increase in the number of daily exchanges of CAPD with IVs ranges from $1200-1500 \mathrm{ml}$. PD was suspended in 6 patients $(60 \%)$ for an average of 40 days ( 21 days - 60 days), 2 withdrawals from the technique were reported after the 2 nd recurrence (20\%). PD was stopped straight away in 1 patient with a hypo-permeable peritoneum with unsatisfactory residual renal function and a second who freely chose to stay in HD. The clinical cases presented show the great variability of FPP in terms of clinical and radiological presentation and therapeutic management, and focus on the significant risk of a transient or permanent withdrawal from the technique. According to literature data, Video-assisted thoracoscopic surgery appears to be promising in the event of failure of conservative treatment, and will thus prolong the survival of the technique.
\end{abstract}

\section{Keywords}

Pleuroperitoneal Leaks, Peritoneal Dialysis, Dyspnea, High Intra-Abdominal Pressures, Technique Survival 


\section{Introduction}

With the increasing use of peritoneal dialysis as a replacement therapy for chronic renal failure, the number of PD-related complications has also increased, including PLL which is a rare, but serious complication of PD. The first case of PPL is credited to Edward, Unger, Finn and Jowett in the 1960s [1].

The prevalence of this complication is highly variable, ranging from $1.6 \%$ of cases [2], up to $10 \%$ of cases [3]. The actual frequency seems to be much higher because a not insignificant number of PPL can go unnoticed and remain asymptomatic.

PLL is the result of congenital or acquired communication between the 2 peritoneal and pleural cavities, and is often linked to high IAP. In general, right-sided pleural effusion, transudative in nature develops right after the initiation of the PD or within a few days post-treatment, although cases have been described with a long latent period [3].

Diagnosis is often clinical and biological although there are various imaging techniques available to confirm PLL in case of diagnostic doubt.

Management of PLL involves the discontinuation of peritoneal dialysis, pleurodesis with sclerosing agents, and the surgical approach. However, no guidelines for PPL have been developed to date, management depends on the severity of the clinical presentation and the need to continue the PD technique [4] [5].

The goal of our work is to reveal the prevalence of this complication in our center, determine the difference in risk factors, and assess the impact on the survival of the technique.

\section{Material and Methods}

This is a retrospective study of 199 peritoneal dialysis patients followed in the Nephrology, Dialysis and Kidney Transplantation Department of Ibn Sina University Hospital in Rabat, from 2006 to 2019.

Included in the study were patients who developed PPL during their treatment with PD. Patients who did not present PLL during PD treatment and patients with insufficient data were excluded.

PPL was suspected due to dyspnea, cough, radiological effusion, and confirmed by improvement after the decrease in infusion volume or by puncture of $\mathrm{PF}$ as well as peritoneography.

All data were collected from patient files and transmitted on operating sheets processed manually.

We noted the various demographic, clinical and paraclinical data: age, sex, body size, time between the start of exchanges and the appearance of PPL, the methods of PD: Automated PD (APD) or Continuous Ambulatory PD (CAPD), the type of $\mathrm{PD}$ catheter implanted, the infusions volumes, the glucose concentrations of the solutions used as well as the parameters: IAP and PET (Peritoneal equilibration test).

The delay between the start of the exchanges and the appearance of the PPL, 
allowed us to divide the sample into 2 groups, a group of early PPL with a delay $<90$ days and a 2 nd group of late PPL with a delay $>90$ days.

We analyzed the modes of clinical revelation, the diagnostic means, the therapeutic management as well as the evolution of our patients.

\section{Results}

Over a period of 13 years (2006-2019), 10 cases of PPL were identified, i.e. a prevalence of $5 \%$.

The distribution by sex is $60 \%$ women and $40 \%$ men, i.e. a sex ratio: 1.5 . The average age of onset of the technique was 49.2 years old (33 - 72 years old).

The indication for PD was by free choice in 7 patients (70\%), and by vascular exhaustion in 3 patients (30\%).

No cystic disease was noted in our patients.

Overweight $(25<\mathrm{BMI}<30)$ concerned 4 patients or $40 \%$ of the total, the rest of the patients were within the normal ranges $(18.5<\mathrm{BMI}<25)$.

All of our patients had a "pigtail" Tenckhoff catheter, and were on CAPD.

The average time to onset of PPL was 76 months, including 4 cases of early PPL (average time of 25 days) and 6 cases of late PPL (average time of 4 years).

We evoked the diagnosis of PPL in front of dyspnea alone in 5 cases (50\%), dyspnea combining cough in 4 cases (40\%), cough alone in 1 case (10\%), and also due to the drop in ultrafiltration volumes reported in 4 patients (40\%).

Intermediate and hypertonic glucose solutions $(2.27,3.86)$ were used in only 4 cases (40\%).

An umbilical hernia was reported in 1 patient (having its cure at the same time as the operation of the PD catheter placement).

An abdominal surgery, type of cholecystectomy was noted in one patient (20 years before dialysis). However, no history of chronic lung disease or bariatric surgery has been reported in our patients.

Intraperitoneal hydrostatic pressure was only performed in 3 patients with values ranging from $17-19 \mathrm{cmH}_{2} \mathrm{O}$, indicating lower infusion volumes before the onset of PPL.

The results of the PET test revealed that five patients had a moderate hyper-permeable peritoneum (i.e. 50\%), three had a moderate hypo-permeable peritoneum (corresponding to $30 \%$, the test was not done in the rest of the patients.

None of our patients presented with peritonitis before the PPL, however 4 patients manifested it a posteriori, of which an episode occurred 10 days after the resumption of exchanges.

As for the radiological diagnosis, the standard radiograph revealed a right effusion in 7 patients (70\%), bilateral in 2 patients (20\%) and left in 1 single patient (10\%).

Exploratory puncture of PF was performed in 3 patients, and showed a PD fluid rich in glucose. 
Peritoneography was performed in 2 patients. However, the methylene blue test or peritoneal scintigraphy was not used to confirm PPL.

The drop in infusion volumes was required in 4 patients (40\%) with an increase in the number of daily exchanges of CAPD with IVs ranges from 1200 $1500 \mathrm{ml}$

PD was suspended in 6 patients (60\%) for an average of 40 days (21 days - 60 days), 2 withdrawals from the technique were reported after the 2 nd recurrence (20\%). PD was stopped straight away in 1 patient with a hypo-permeable peritoneum with unsatisfactory residual renal function (case 4) and a second who freely chose to stay in HD (case 5).

The chemical pleurodesis was proposed in the 2 patients who had an immediate PPL (Case 8 and Case 10), unless they have expressed a disclaimer at the last minute (see Table 1).

After an average decline of 5 years, the evolution of our patient samples was marked by: a kidney transplant from a living donor for cases 4, 9, 6 after delays of: 12 months 10 months and 36 months respectively.

Case 2 is still on peritoneal dialysis; no recurrence of the leak was noted.

Cases 5, 7, 8 and 10 received hemodialysis via a permanent catheter after stopping PD and have since been lost.

Cases 1 and 3 died of cardiovascular causes and complicated pneumonia of septic shock respectively after a delay of 36 months and 9 months.

Table 1. Descriptive table of our patient sample.

\begin{tabular}{|c|c|c|c|c|c|c|c|c|c|c|}
\hline & Case 1 & Case 2 & Case 3 & Case 4 & Case 5 & Case 6 & Case7 & Case 8 & Case 9 & Case 10 \\
\hline Methods of PD & CAPD & CAPD & CAPD & CAPD & CAPD & CAPD & CAPD & CAPD & CAPD & CAPD \\
\hline Delay PD-PPL & 6 months & 12 months & 14 months & 13 months & 2 months & 21 days & 4 months & 2 days & 2 years & 16 days \\
\hline Diagnosis & $\begin{array}{l}\text { Clinical } \\
\text { Ch radio }\end{array}$ & $\begin{array}{c}\text { Clinical } \\
\text { UF reducing } \\
\text { Ch radio } \\
\text { P.P }\end{array}$ & $\begin{array}{l}\text { Clinical } \\
\text { UF reducing } \\
\text { Ch radio }\end{array}$ & $\begin{array}{c}\text { Clinical } \\
\text { UF Reducing } \\
\text { Ch radio } \\
\text { P-graphy }\end{array}$ & $\begin{array}{c}\text { Clinical } \\
\text { Ch radio }\end{array}$ & $\begin{array}{l}\text { Clinical } \\
\text { Ch radio } \\
\text { P-graphy }\end{array}$ & $\begin{array}{l}\text { Clinical } \\
\text { Ch radio } \\
\text { P.P }\end{array}$ & $\begin{array}{l}\text { Clinical } \\
\text { Ch radio }\end{array}$ & $\begin{array}{l}\text { Clinical } \\
\text { UF reducing } \\
\text { Ch radio }\end{array}$ & $\begin{array}{l}\text { Clinical } \\
\text { Ch radio } \\
\text { P.P }\end{array}$ \\
\hline Localisation & Right & Right & Left & Right & Bilateral & Bilateral & Right & Right & Right & Right \\
\hline Management & $\begin{array}{l}\text { Decrease in } \\
\text { IV:1200 }\end{array}$ & $\begin{array}{l}\text { Decrease in } \\
\text { IV:1500 }\end{array}$ & $\begin{array}{l}\text { Transient } \\
\text { stop PD }\end{array}$ & Stop PD & Stop PD & $\begin{array}{l}\text { Decrease in } \\
\text { VI:1300 }\end{array}$ & $\begin{array}{l}\text { Transient } \\
\text { stop PD }\end{array}$ & Stop PD & $\begin{array}{l}\text { Transient } \\
\text { stop PD }\end{array}$ & $\begin{array}{l}\text { Decrease in } \\
\text { IV: } 1200 \\
\text { Stop PD > } \\
\text { recurrence }\end{array}$ \\
\hline Evolution & $\begin{array}{c}\text { Resumption } \\
\text { PD }\end{array}$ & $\begin{array}{l}\text { Resumption } \\
\text { PD }\end{array}$ & $\begin{array}{l}\text { Resumption } \\
\text { PD }\end{array}$ & Switch HD & $\begin{array}{c}\text { Switch } \\
\text { HD }\end{array}$ & $\begin{array}{c}\text { Resumption } \\
\text { PD }\end{array}$ & $\begin{array}{c}\text { Switch HD > } \\
\text { recurrence }\end{array}$ & $\begin{array}{l}\text { Switch } \\
\text { HD > re- } \\
\text { currence }\end{array}$ & $\begin{array}{l}\text { Resumption } \\
\text { PD }\end{array}$ & $\begin{array}{l}\text { Switch } \\
\text { HD > re- } \\
\text { currence }\end{array}$ \\
\hline
\end{tabular}

Ch radio: Chest radio; P.P: pleural puncture; IV: infusion volume; P-graphy: peritoneo-graphy.

\section{Discussion}

PPL is a rare, but serious complication of PD, although generally not lifethreatening. On many occasions, it forces the patient to withdraw from PD and to accept a temporary or permanent transfer to hemodialysis (HD). The first case of PPL is credited to Edward, Unger, Finn and Jowett in the 1960s [1]. Since 
then, other authors have reported similar cases and reported new aspects of this complication [4] [5].

The prevalence of this complication is highly variable, ranging from $1.6 \%$ in the series by Nomoto et al., which reported 50 cases of PPL in a population of $3195 \mathrm{PD}$ patients [2], up to $10 \%$ of cases in the series by Chow et al. [3]. However, in our unit and after 13 years of experience, the prevalence in our series remains lower: $5 \%$.

The actual frequency seems to be much higher because a not insignificant number of PPL can go unnoticed and remain asymptomatic: $25 \%$ [6].

PPL has been described much more often in women [1] [2]. A fact that also matches the results of our series (6 women and 4 men, i.e. a sex ratio: 1.5 ).

It is believed that PPL may be due to congenital or acquired communications between the pleura and the peritoneum. This has been demonstrated both at peritoneal scintigraphy [7] and at autopsy, which shows a localized solution of continuity of diaphragmatic muscle fibers [8]. Elevated IAP with dialysate infusion, in a patient with such communication, promotes translocation of dialysate into the pleural space. IAP arises either transiently with coughing or straining or permanently from a large volume of PD solution [6].

These diaphragmatic abnormalities are generally congenital and straight, explaining the predominance of effusions on the right side [9]. PPL was straight in $70 \%$ of our sample.

Another mechanism that has been postulated is lymph drainage disorders, particularly in the right hemi-diaphragm [8], where this system is most abundant.

The diagnosis of PPL is simple, but clinical suspicion is paramount. Ignorance of this complication leads most often to abandonment and failure of the technique.

The most common clinical manifestation is the onset of dyspnea associated or not with chest pain immediately after the onset of PD or a few days later, although cases have been described with a long latent period [4] [10]. In our sample: $40 \%$ of the reported cases presented early PPL ( $<90$ days), one of which occurred 48 hours after the start of the technique. These cases of early PPL probably represent patients with congenital diaphragmatic abnormalities. The cases which occur later represent a priori those with acquired diaphragmatic defects.

The decrease in ultrafiltration volumes can also testify to the presence of PPL, which indicates that dialysate is collecting in the pleural space, in our serie only 4 of our patients showed a decrease in UF volumes (40\%) [4]. Less common symptoms are weight gain, and hypotension [8], none of our patients showed these 2 clinical signs.

The use of hypertonic dialysate also increases the risk of PPL [11], as this hyperosmolarity produces an osmotic volume flow from the tissues to the peritoneal cavity, thus increasing the IAP [12], however the solutions hypertonic glucose was only used in 4 of our patients (40\%). 
Concerning the predisposing risk factors cited in the literature, we find polycystic kidney disease. This is probably related to the increased IAP in these patients and therefore to higher pleuroperitoneal pressure gradients [13]. In our series there were no patients with polycystic kidney disease.

Unfortunately, IAP was not performed in all of our patients and none of our patients presented an episode of peritonitis before PPL, a fact which cannot confirm the data in the literature implying the increase of IPP in the occurrence of this complication and episodes of peritonitis that would exacerbate peritoneal defects [14]. Shemin et al. reported that $6 \%$ of patients with PPL had at least one episode of peritonitis [15].

No close link has been established between BMI and the occurrence of this complication, which is also consistent with the data in the literature.

No history of bariatric surgery was reported in our series, however, only one umbilical hernia cure took place in the same patient who manifested her PPL 48 hours from the start of the exchange, a percentage which remains insignificant. But which confirms the data in the literature concerning the congenital component of PPL and the participation of weakness of the abdominal wall in its occurrence [7] [8].

Biochemical analysis of PF will reveal a transudate rich in glucose, a high concentration gradient in serum and pleural glucose remains a very sensitive and specific test for diagnosing PPL [16]. This is because no other form of hydrothorax has elevated glucose levels. PD solution in the thoracic cavity presents a unique situation that occurs only in patients receiving PD [6]. The ratio: pleural liquid glucose/serum glucose is very dynamic and varies depending on the type of solution used, the volume of infusion and the stasis time as well, a positive gradient is strongly suggestive of PPL [16]. However, interpretation in diabetic patients remains more difficult [17]. In our context, biochemical analysis confirmed the diagnosis of PPL in 3 patients.

Other diagnostic tests are increasingly practiced and call for peritoneal scintigraphy marked with technetium-99m [18], which is only sensitive in $40 \%$ to $50 \%$ of cases. Contrast computed tomography peritoneography was associated with a sensitivity of $33 \%$ in one study, with an additional risk of nephrotoxicity in patients with residual renal function [19] [20]. The methylene blue test in one study did show no sensitivity and is associated with a risk of chemical peritonitis [21].

In our center, the occurrence of right pleurisy in a patient with PD is an FPP until proven otherwise, such as. The diagnosis is initially based on clinical and radiological progress, after a drop in infusion volumes or even a transient stopping of DP. And secondly on the results of the chemical analysis of the PF. Peritonography was only performed in 2 patients.

No guidelines for PPL have been developed to date, management depends on the severity of the clinical presentation and the need to continue the PD technique, if the patient is very symptomatic and the leak is significant, thoracentesis may be necessary to remove PF, however, and in most cases, lowering the infu- 
sion volumes is usually sufficient.

Sometimes these pleuroperitoneal communications resolve spontaneously after a temporary transfer to hemodialysis for 2 - 8 weeks, but this is usually not the case. In our sample, the percentage of cures with these conservative measures is $50 \%$, that reported in the literature is generally $40 \%$ [22].

For patients who wish to return to the $\mathrm{PD}$ technique, invasive measures are necessary, they consist of chemical pleurodesis via an intercostal drain [16]. Agents used include tetracycline, blood, and fibrin glue. The efficacy of chemical pleurodesis under video-assisted thoracoscopic guidance for hydrothorax has been confirmed, and the success rate was reported to be $90 \%$ [23].

In open thoracotomy, defect in the diaphragm is accessed through a small intercostal incision. Diaphragm is directly visualized and other possible defects can be identified with the concurrent infusion of fluid into the peritoneum. Defect can be repaired with sutures and Teflon patch may be used to reinforce the repair [9].

Video-assisted thoracoscopic surgery has shown great promise for the management of this complication [16] [21]. Its efficacy has been confirmed by several case series from various centers and the demonstration of a success rate in excess of $90 \%$. With accumulation experience using the thoracoscopic technique, it remains to be seen whether this mode of treatment will obviate the traditional closed pleurodesis [9].

\section{The Limitations of the Study}

However, some limitations of the study should be noted, first IAP and PET have not been measured in all patients since there was only one nurse specializing in peritoneal dialysis, and this until 2017.

During the first years of peritoneal dialysis, the majority of patients were on CAPD as there was not enough DPA cycler available. The conservative approach was very limited by the drop in infusion volumes, and the withdrawal of the technique for fear of under dialysis was the rule.

This is a retrospective study, patient follow-up was limited since there were many patients lost to follow-up, especially those transferred to hemodialysis.

The reluctance of patients to undergo surgery and the absence of surgically resolved cases in our series strongly impacts the therapeutic management of PPL.

Despite all the above obstacles, we were able to have original adaptation strategies.

\section{Conclusions}

PPL is a complication which remains exceptional, but a serious complication of $\mathrm{PD}$ that can compromise the survival of the technique.

Our clinical cases presented in this paper identify the great variability of PPL in terms of clinico-radiological presentation and therapeutic management, in- 
cluding conservative measures, and focus on the significant risk of a transient or definitive exit of the technique.

The diagnosis is clinico-biological. PL is an essential test to confirm the diagnosis, especially when it comes to late PPL.

No guidelines for PPL have been developed to date, management depends on the severity of the clinical presentation and the need to continue the PD technique, if the patient is very symptomatic and the leak is significant.

Video-assisted thoracoscopic surgery appears to be promising in the event of failure of conservative treatment, and will thus prolong the survival of the technique.

\section{Conflicts of Interest}

The authors declare no conflicts of interest regarding the publication of this paper.

\section{References}

[1] Edwards, S.R. and Unger, A.M. (1967) Acute Hydrothorax-A New Complication of Peritoneal Dialysis. Journal of the American Medical Association, 199, 853-855. https://doi.org/10.1001/jama.199.11.853

[2] Nomoto, Y., Suga, T., Nakajima, K., Sakai, H., Osawa, G., Ota, K., Kawaguchi, Y., et al. (1989) Acute Hydrothorax in Continuous Ambulatory Peritoneal Dialysis-A Collaborative Study of 161 Centers. American Journal of Nephrology, 9, 363-367. https://doi.org/10.1159/000167997

[3] Chow, C.C., Sung, J.Y., Cheung, C.K., Hamilton-Wood, C. and Lai, K.N. (1988) Massive Hydrothorax in Continuous Ambulatory Peritoneal Dialysis. Diagnosis, Management and Review of the Literature. The New Zealand Medical Journal, 101, 475-477.

[4] Holm, J., Lieden, B. and Lindgust, B. (1971) Unilateral Effusion a Rare Complication of Peritoneal Dialysis. Scandinavian Journal of Urology and Nephrology, 5, 84-85. https://doi.org/10.3109/00365597109133582

[5] Winchester, J. and Kriger, F.L. (1994) Fluids Leaks: Prevention and Treatment. Peritoneal Dialysis International, 14, S43-S47. https://doi.org/10.1177/089686089401403S09

[6] Bae, E.H., Kim, C.S., Choi, J.S. and Kim, S.W. (2011) Pleural Effusion in a Peritoneal Dialysis Patient. Chonnam Medical Journal, 47, 43-44. https://doi.org/10.4068/cmj.2011.47.1.43

[7] Tokmak, H., Mudun, A., Turkmen, C., Sanli, Y., Cantez, S. and Bozfakioglu, S. (2006) The Role of Peritoneal Scintigraphy in the Detection of Continuous Ambulatory Peritoneal Dialysis Complications. Renal Failure, 28, 709-713. https://doi.org/10.1080/08860220600925396

[8] Garcia Ramon, R. and Miguel Carrasco, A. (1998) Hydrothorax in Peritoneal Dialysis. Peritoneal Dialysis International, 18, 5-10. https://doi.org/10.1177/089686089801800101

[9] Chow, K.M., Szeto, C.C. and Li, P.K. (2003) Management Options for Hydrothorax Complicating Peritoneal Dialysis. Seminars in Dialysis, 16, 389-394. https://doi.org/10.1046/j.1525-139X.2003.16080.x

[10] Bargman, J. (1994) Non-Infectious Complications of Peritoneal Dialysis. In: Gokal, 
R. and Nolph, K.D., Eds., The Textbook of Peritoneal Dialysis, Kluwer Academic, Boston, 557-560. https://doi.org/10.1007/978-94-011-0814-0 19

[11] Szeto, C.C. and Chow, K.M. (2004) Pathogenesis and Management of Hydrothorax Complicating Peritoneal Dialysis. Pulmonary Medicine, 10, 315-319.

https://doi.org/10.1097/01.mcp.0000127901.60693.d0

[12] Zakaria, E.R., Lofthouse, J. and Flessner, M.F. (2000) Effect of Intraperitoneal Pressures on Tissue Water of the Abdominal Muscle. The American Journal of Physiology-Renal Physiology, 278, F875-F885.

https://doi.org/10.1152/ajprenal.2000.278.6.F875

[13] Fletcher, S., Turney, J.H. and Brownjohn, A.M. (1994) Increased Incidence of Hydrothorax Complicating Peritoneal Dialysis in Patients with Adult Polycystic Kidney Disease. Nephrology Dialysis Transplantation, 9, 832-833.

[14] Garcia-Maldonado, B., Guerrero-Ortiz, M., Gomez-Fuente, J.R., Garofano-Lopez, R., Prados-Soler, M.C., Pino, Y.D. and Pino, M.D. (2012) Pleuroperitoneal Communication in Peritoneal Dialysis Patient. Nefrologia, 32, 551-552.

[15] Shemin, D., Clark, D.D. and Chazan, J.A. (1989) Unexplained Pleural Effusions in the Peritoneal Dialysis Population. Peritoneal Dialysis International, 9, 143-144. https://doi.org/10.1177/089686088900900213

[16] Chow, K.M., Szeto, C.C., Wong, T.Y. and Li, P.K. (2002) Hydrothorax Complicating Peritoneal Dialysis: Diagnostic Value of Glucose Concentration in Pleural Fluid Aspirate. Peritoneal Dialysis International, 22, 525-528. https://doi.org/10.1177/089686080202200416

[17] Tapawan, K., Chen, E., Selk, N., Hong, E., Virmani, S. and Balk, R. (2011) A Large Pleural Effusion in a Patient Receiving Peritoneal Dialysis. Seminars in Dialysis, 24, 560-563. https://doi.org/10.1111/j.1525-139X.2011.00859.x

[18] Kang, T.W. and Kim, C.K. (2009) Pleuroperitoneal Communication of Peritoneal Dialysis Demonstrated by Multidetector-Row CT Peritoneography. Abdominal Imaging, 34, 780-782. https://doi.org/10.1007/s00261-008-9468-5

[19] Cho, Y., D'Intini, V. and Ranganathan, D. (2010) Acute Hydrothorax Complicating Peritoneal Dialysis: A Case Report. Journal of Medical Case Reports, 4, 355. https://doi.org/10.1186/1752-1947-4-355

[20] Pankaj, P., Pathak, V., Sen, I.B., Verma, R., Bhalla, A.K., Marwaha, A. and Pandey, S. (2005) Use of Radionuclide Peritoneography in the Diagnosis of Pleuroperitoneal Communication as a Complication of Continuous Ambulatory Peritoneal Dialysis. Indian Journal of Nuclear Medicine, 20, 4-8. https://doi.org/10.1093/ndt/gfi1118

[21] Tang, S., Chui, W.H., Tang, A.W., Li, F.K., Chau, W.S., Ho, Y.W., Chan, T.M. and Lai, K.N. (2003) Video-Assisted Thoracoscopic Talc Pleurodesis in Effective for Maintenance of Peritoneal Dialysis in Acute Hydrothorax Complicating Peritoneal Dialysis. Nephrology Dialysis Transplantation, 18, 804-808. https://doi.org/10.1093/ndt/gfg042

[22] Abraham, G., Shokker, A., Blake, P. and Oreopoulos, D.G. (1988) Massive Hydrothorax in Patients on Peritoneal Dialysis: A Literature Review. Advances in Peritoneal Dialysis, 4, 121.

[23] Krivokuca, I., Lamemrs, J.W.J. and Kluin, J. (2009) Peritoneal Dialysis-An Unusual Cause of Pleural Effusion ("Sweet Hydrothorax"). Respiratory Medicine CME, 2, 197-200. https://doi.org/10.1016/j.rmedc.2008.12.001 